\title{
Estrategias de Preservación del Patrimonio Cultural de los Centros Históricos de Puebla, La Habana y Quito
}

\section{Preservation Strategies of the Cultural Heritage of the Historical Centers of Puebla, Havana and Quito}

\author{
Norma Leticia Ramírez-Rosete \\ normaleticia.ramirez@correo.buap.mx @ https://orcid.org/0000-0002-3268-8757 \\ Benemérita Universidad Autónoma de Puebla, México 72000 \\ Ciudad Universitaria, Blvd. Valsequillo s/n, 72570, Puebla, México. \\ $M^{a}$ Jesús González-González \\ mjgong@unileon.es@ https://orcid.org/0000-0002-3639-3446 \\ Universidad de León, España \\ Avenida de la Universidad, 24007 León, España \\ José Alejandro Reyes-Granados \\ alexco@hotmail.com (1) https://orcid.org/0000-0002-3277-5818 \\ Universidad de Valladolid, España \\ Prado de la Magdalena, s/n, 47011 Valladolid, España
}

\section{INFO ARTÍCULO}

Recibido: 5/11/2018

Revisado: 29/07/2019

Aceptado: 03/11/2019

\section{PALABRAS CLAVE}

Centros Históricos

Patrimonio Cultural

Conservación del Patrimonio

\section{KEYWORDS}

Historical Centers

Cultural Heritage

Heritage Conservation

\section{RESUMEN}

Esta investigación se sustenta en una metodología descriptiva respecto a las principales características tipológicas urbano-arquitectónicas de las ciudades históricas de Puebla, La Habana y Quito, haciendo énfasis en la legislación actual y políticas de conservación para su protección. Esto debido a sus complejas y diversificadas funciones político-administrativas, culturales, turísticas etc., que siguen manteniendo cierta homogeneidad. No obstante, algunas intervenciones ponen en riesgo la conservación y preservación de su patrimonio cultural material e inmaterial. Por lo tanto, esta investigación está enfocada a analizar y comparar los planes regulatorios y herramientas de planeación dirigidos tanto a la mercantilización como a la rehabilitación de la identidad cultural de estas ciudades novohispanas que cumplen actualmente un papel relevante como ciudades patrimonio cultural de la humanidad referentes a nivel mundial.

\begin{abstract}
This research is based on a descriptive methodology regarding the main urban-architectural typological characteristics of the historic cities of Puebla, Havana and Quito, emphasizing current legislation and conservation policies for their protection. This is due to its complex and diversified political-administrative, cultural, tourist, etc. functions, which continue to maintain a certain homogeneity. However, some interventions jeopardize the conservation and preservation of their tangible and intangible cultural heritage. Therefore, this research is focused on analyzing and comparing regulatory plans and planning tools aimed at both the commercialization and the rehabilitation of the cultural identity of these Novo-Hispanic cities that currently play a relevant role as cultural heritage cities of humanity references Worldwide.
\end{abstract}




\section{INTRODUCCIÓN}

La revolución industrial provoco serias transformaciones en el tejido social y estructura de las ciudades de Europa, misma que estimulo el surgimiento del sentimiento de apego a los valores históricos y de apropiación de la cultura, el cual fue manifestado en 1931 en la Carta de Atenas y más tarde en 1964 en la Carta de Venecia, en donde se establecieron los principios de restauración y conservación de monumentos y sitios históricos, así como las bases para los nombramientos (Biffis, 2013). Estos documentos iniciaron una serie de acciones para la protección y preservación de las ciudades históricas. En la actualidad, los centros históricos de Puebla, La Habana y Quito, han tenido un papel relevante en la reactivación económica y social de las ciudades gracias a su esencia histórica y cultural. No obstante, ciertas interacciones provocan una serie de conflictos de intereses en torno a estos espacios con respecto a las diferentes dinámicas urbanas que cada ciudad posee, haciendo al objeto de estudio aún más atractivo. Por lo tanto, la gestión de los centros históricos es una compleja tarea a causa de la diversidad de realidades, situaciones y de actores, producto de los procesos que han atravesado, por ejemplo; un centro histórico europeo no posee las mismas características que uno latinoamericano, estas diferencias se presentan entre distintos países e incluso entre distintas ciudades de un mismo país y regiones.

En general, la problemática de la protección de centros históricos ha sido un tema crucial para las políticas urbanas en América Latina. Por lo tanto, en este estudio comparativo de las estrategias de preservación del patrimonio cultural de los centros históricos objeto de investigación, se mostrarán las acciones encaminadas a su protección dentro de los planes de cada ciudad. Entre las problemáticas que afrontan está el creciente deterioro provocado por la misma naturaleza y por situaciones económico-sociales que actúan en el proceso de modernización y promoción turística de la ciudad, además de que conllevan a la degradación de las condiciones de vida por la falta de servicios básicos y dotación de equipamiento para los estratos sociales más vulnerables incluidos los barrios históricos. Por lo anterior, es de gran importancia hacer conciencia respecto a la regulación que promueva el desarrollo y conservación de los centros históricos de nuestras ciudades históricas.

\section{METODOLOGÍA}

La metodología surge de un proceso analítico descriptivo basada en la observación y análisis de la información bajo un enfoque sistémico. En este sentido se ha recurrido a una revisión cartográfica, así como documentos oficiales que corresponden a planes y proyectos para reflexionar respecto a la evolución histórica urbano-arquitectónica de dichos asentamientos. En el caso del centro histórico de La Habana, Cuba, se revisaron las acciones ejercidas desde el año1983 hasta la actualidad como el Plan Especial de Desarrollo Integral, PEDI (2016-2030). Respecto a la ciudad de Puebla se tomaron los planes reguladores y acciones del año 1987 al 2015 y por último para la ciudad de Quito se analizó el periodo de 1967 hasta el año 2004 tomando como referencia el plan Odriozola. Así mismo en el marco de referencia se analizaron artículos científicos digitales para la obtención de datos relevantes por parte de expertos en la materia, además de que se incluyeron algunos mapas antiguos como apoyo visual para identificar su morfología histórica y traza urbana de diversas fuentes y programas de intervención de cada una de estas ciudades. Cabe destacar que este estudio tiene un carácter participativo como producto de la investigación-acción, ya que los autores han sido participantes directos y espectadores activos del impacto actual de las políticas en el patrimonio tangible, diseñando herramientas de diseño participativo a través de visitas de campo y aplicación de entrevistas a los actores clave y tomadores de decisiones que intervienen en las situaciones y realidades que se producen. De esta manera, a través de la recopilación y el análisis de la información, se logró la identificación y diferenciación de las acciones para la preservación y conservación del patrimonio cultural en estos países en cuanto a los procesos de transformación desde su fundación hasta la actualidad.

Por lo tanto, esta investigación se integra de tres secciones, la primera consiste en un marco de referencia en donde se definirán y analizaran términos y conceptos clave que nos ayudaran a orientar esta investigación, tales como urbanismo patrimonial, protección, conservación y rehabilitación urbana de los centros 
históricos, tema crucial para la implementación de políticas urbanas en beneficio del patrimonio cultural. Además de mencionar brevemente la historia de la fundación de estas ciudades novohispanas, así como sus características principales, planificación y estructura urbana con la finalidad de entender el contexto de su desarrollo desde sus inicios hasta la actualidad. En la segunda sección, se realizará una comparación de los planes regulatorios, herramientas de planeación, preservación y rehabilitación de las tres ciudades declaradas patrimonio cultural de la humanidad Quito, La Habana y Puebla, para posteriormente analizar los diferentes enfoques metodológicos de donde se desprenden las principales estrategias de planeación y preservación del patrimonio cultural para estas ciudades y su incidencia. Finalmente, se plantea un apartado de resultados y conclusiones, donde se discuten los alcances, perspectivas e impactos en función de identificar en los instrumentos de conservación las estrategias de preservación del patrimonio cultural.

\section{REFLEXIÓN TEÓRICA}

Gran parte de las urbanizaciones en el mundo son el resultado del crecimiento de antiguos asentamientos que tuvieron un gran impacto en su origen. Es importante señalar que existen muchos conceptos tales como urbanismo patrimonial que es relativamente reciente, pero de gran relevancia en los centros históricos, ya que surge a partir de la reconstrucción de las ciudades de posguerra en Europa y la protección de la ciudad histórica. Diferentes términos se emplean para definir el fenómeno del urbanismo patrimonial como Centro Histórico y la protección urbana, uno de los mayores aportadores de este tema fue Camilo Sitte (18431903) quien puso en primer lugar al ambiente de las ciudades antiguas, además de que la ciudad moderna debía restablecer los valores de la ciudad tradicional, fundamentando así su rechazo proyectos del tipo de Haussmann (Plan Urbano de Paris, 1850-1870), en donde el criterio de protección de la ciudad histórica fue inexistente (Echeverria, 2008). Gracias a este proyecto y al crecimiento junto con las transformaciones de las ciudades, nació la esencia de la ciudad histórica y su sentido de identidad, aunado a esto, se comenzó a desarrollar la conciencia de la existencia del urbanismo patrimonial y su cualidad de monumento, surgiendo así los "modernos" centros históricos (Carta del Restauro de 1972). De esta manera, el concepto de urbanismo patrimonial se amplió, dando cabida a mas autores que tomaron este concepto para definirlo, como Jorge Enrique Hardoy, que conceptualiza diferentes tipos de urbanismo patrimonial - en áreas históricas latinoamericanas-, según cuatro escalas fundamentales: la ciudad histórica, el pueblo histórico, el centro histórico y los conjuntos históricos (Tojo, 2000).

Por otra parte, el tema rehabilitación urbana es producto de la evolución de las ciudades, teniendo su origen a mediados de los años cincuenta (Val, 2011), durante la crisis del crecimiento indefinido que dio cabida a la zonificación de las partes antiguas de las ciudades más modernas, las décadas de los sesenta y el setenta fueron importantes para el desarrollo de este término ya que fue en esta época en donde se despertó el interés de la preservación y conservación de los centros o cascos históricos, surgiendo así las intervenciones en áreas urbanas históricas por lo que este concepto está muy ligado a la restauración de monumentos arquitectónicos. Con el tiempo la teoría de la rehabilitación urbana paso a ser una opción urbanística centrándose en la ciudad existente, haciendo prevalecer la transformación sobre la conservación del carácter histórico de la ciudad (Tojo, 2000).

Para el siglo XX el termino de urbanismo histórico fue reafirmándose hasta ser reconocido por primera vez con la precisión de la expresión que abarca el tema de protección de bienes (Rodríguez, 2008). Asimismo, el patrimonio cultural es definido por la Organización de las Naciones Unidas para la Educación, la Ciencia y la Cultura (UNESCO, 2019) -por sus siglas en inglés- como el legado que recibimos del pasado, que se vive en el presente y que además se transmitirá a las nuevas generaciones. Cabe destacar que el patrimonio cultural no solo es referido a los monumentos y objetos, también este comprende las expresiones, maneras de interpretar y ver al mundo, costumbres, rituales, festividades, saberes y técnicas, que identifica a un grupo social y que corresponde a su patrimonio cultural intangible o inmaterial. Por consiguiente, existe una preocupación latente por la tradición, que corresponde a el temor por perder nuestra propia identidad y junto con eso nuestro individualismo. De esta manera el patrimonio cultural debe estar en constante interacción con la política pública y la sociedad para que este pueda obtener un valor equitativo por estas partes, que a 
pesar de los enfoques que le de cada uno la finalidad mutua sea contribuir a su conservación y salvaguarda de acuerdo con las políticas implementadas en cada lugar.

\section{ANTECEDENTES HISTÓRICOS}

\section{La fundación, planeación y estructura de las ciudades novohispanas en América Latina}

La fundación de las ciudades novohispanas funciono como un instrumento de transformación social a través de la imposición de religiones, ideas, cultura y política a causa de un proceso de colonización basado en el establecimiento de factores comerciales, las cuales influyeron en aspectos urbanos y sociales. La función principal de las nuevas ciudades era la ocupación del territorio que posteriormente permitiría su colonización ocasionando un patrón urbano con rasgos uniformes que se extendió desde Nuevo México en el Norte hasta Chile y Argentina, Colombia y Cuba en el extremo sur y este del continente (Rocha, 2011). Desde los primeros años del siglo XVI se dieron instrucciones sobre la planeación de las ciudades mediante una ordenanza que es la agrupación de normas u órdenes que regulan el funcionamiento de una ciudad o comunidad. Las Ordenanzas aconsejaban que se eligiera un sitio de fundación llano preferentemente próximo al agua (Nicolini, 2005). Estas leyes favorecían la fundación de nuevas poblaciones procurando que el mayor número de pobladores fueran agricultores y ganaderos, además que la repartición de tierras habría de hacerse según la calidad de los pobladores, según sus méritos o servicios prestados y según si fueren o no de los primeros. Entre sus principales atribuciones abarcan materias relativas al emplazamiento, organización y protección de futuros habitantes de las ciudades: salubridad, facilidad de comunicaciones con la metrópoli, indios próximos a evangelizar, agua cercana y fácil de conducir, materiales no lejanos para edificar, así como tierras de labor y cultivo en las inmediaciones del terreno libre de ocupación. La influencia española en los cascos históricos de las ciudades novohispanas y en concreto en las ciudades de Puebla, Quito y La Habana está muy bien definida a través de estas ordenanzas.

Más tarde se producen cambios en la estructura urbana del sistema de centros en América Latina durante el periodo independentista, los elementos urbanos fundamentales habían quedado definidos desde fines del siglo XVI. La red urbana es estática en las fronteras interiores con pocas alteraciones en las líneas de transporte terrestre y marítimo durante siglos (Hardoy y Geisse, 1972). Con respecto a la población total de América no era equiparable a la que existía al producirse la conquista, en el año1800, Salvador y México eran las únicas ciudades de América Latina con más de 100000 habitantes. En 1900 la población se duplicó de 1.5 a 3 habitantes por km2, mientras que América hispánica sumaba 43.5 millones y su urbanización entre 1860 y 1870, lo cual se debió al crecimiento poblacional y la expansión económica debido a la inversión de capitales extranjeros, inmigración europea, e incorporación a los mercados mundiales (Gormsen, 1993). De esta forma, el incremento de la población urbana al final del siglo XX obedece al aumento de las migraciones internas del campo a la ciudad, la orientación económica y desarrollo regional, y a las áreas territoriales reducidas donde se concentran las inversiones en industrias y servicios (Hardoy, J. E. y Geisse, G., 1972). Por lo tanto, podemos afirmar que urbanísticamente los países de América Latina no han seguido las etapas clásicas de las economías actualmente desarrolladas e industrializadas. En la distribución de su población y en la estructura interna de sus ciudades reflejan el brusco paso de un capitalismo incipiente nacional sin poder o influencia suficiente para impulsar el crecimiento económico con muchas desigualdades internas durante las últimas décadas (Martin y Múscar, 1992). En resumen, el crecimiento de la mayoría de las áreas metropolitanas está asociado con la concentración de funciones económicas y administrativas originadas durante el periodo colonial (Duviols, 1999).

Hay que destacar que la traza o primer reparto de la ciudad tenía entre otros objetivos la división de la población española de la indígena, lo que hacía posible y eficaz una verdadera evangelización. Durante la fundación de las ciudades en América, los colonizadores fueron experimentando los criterios de las directrices urbanísticas, políticas y expansivas (Diaz del Castillo, 1998). De esta manera, la estructura urbana en damero, desde su aparición en América a fines del siglo XV hasta (Rocha, 2011) nuestros días, ha sabido adaptarse a las diferentes corrientes de modernidad, transformación y destrucción, consiguiendo que la estructura 
urbana tuviera la capacidad de soportar cambios sin perder la identidad ni la calidad. Asimismo, se atienden a las necesidades higiénicas, administrativas, comerciales, agrícolas y defensivas de las nuevas poblaciones. Vale la pena decir que las leyes de Indias y la sencillez del plano de ajedrez permitió un fácil reparto de los solares (Lucena, 2008).

Después de la conquista se comienza a planificar con las Ordenanzas de 1573, donde la traza de las nuevas ciudades se basaba en el plano en damero que se representa en forma de tablero de ajedrez con 100 metros de longitud por lado (cuadras o manzanas). "El estilo barroco es relevado por el neoclasicismo, con el que se identifican los jóvenes estados latinoamericanos tras la independencia" (Heineberg, 1996), de esta manera, la vitalidad de las principales ciudades emana del ímpetu que diverge a partir de los centros históricos. Ciudades como La Habana, Quito, Lima, Puebla o México constituidos durante el siglo XVI, conservan actualmente su valor del patrimonio cultural tangible originario de la época colonial, así como sus características de su trazado original: "como son la dimensión de las manzanas, los solares, la localización de los espacios públicos, la sede de los edificios de gobierno y en torno al núcleo fundacional, la organización de los barrios junto a edificaciones civiles y religiosas" (Sahady \& Gallardo, 2004) (figura 1).

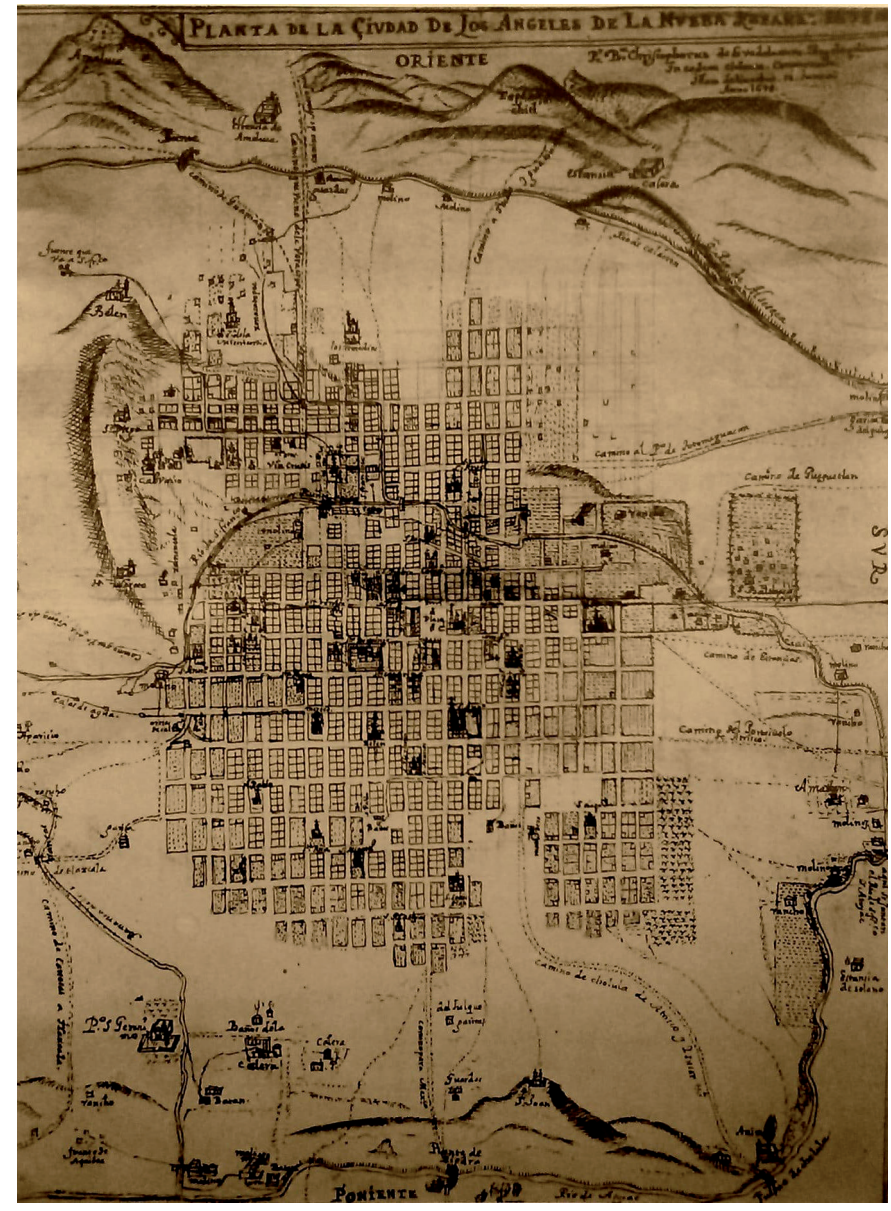

Figura 1. Mapa de la Ciudad de Puebla 1698. Fuente: Fuentes, 2011.

No obstante, cabe destacar que tanto las características como la organización de espacios, escala, centralismo, apertura y ortogonalidad, existían en América Latina previas a la colonización europea. De esta manera, se utilizaron distintos tipos de planos urbanos: ciudades irregulares antiguas fundadas por los españoles sin plan preestablecido, entre ellas Loja (Quito); ciudades semirregulares que son las más comunes en la urbanización de la América española y regular o tablero de ajedrez, ubicado respecto a los 4 puntos cardinales. Simultáneamente, la iglesia era orientada litúrgicamente en la fachada de poniente de la plaza mayor. Más adelante, en la legislación existente se daban las dimensiones que debían tener las cuadras (se parcelaban en forma de cruz), calles y plazas. Mientras que en el siglo XVIII se modifica dando a los lotes más profundidad y combinándolos dentro de la superficie cuadrada o rectangular de la cuadra, este nuevo reparto era lógico y sobre todo en las colonias agrícolas (Landaeta \& Espinoza, 2013).

\section{RESULTADOS: INFLUENCIA DE ESPAÑA EN LAS CIUDADES HISTÓRICAS DE AMÉRICA LATINA}

Al llegar a América los españoles y los portugueses tenían sus propias teorías y experiencias sobre donde ubicar y como construir una ciudad, sin embargo, la novedad de la realidad americana les impuso modificaciones a sus criterios con ciertos modelos sobre las formas de la ciudad colonial que serían repetidos durante varios siglos. En los cascos históricos latinoamericanos aumentó el comercio internacional, industrialización y construcción de líneas ferroviarias en el siglo XIX. La demanda de bienes y servicios ha reforzado estos centros urbanos. De esta manera, los factores que influyeron para la creación de las nuevas ciudades fue la concepción del espacio urbano prehispánico (Rocha, 2011)

A partir del siglo XX la ciudad se expande y con el cambio de uso del suelo hay una gran demanda de locales comerciales que llevaron a techar los patios interiores reduciendo el espacio disponible para vivienda. El uso 
comercial y de servicios provoca el derribo de las casas antiguas y construcción de edificios más amplios y altos. Se produce un proceso de concentración económico- administrativo que lleva a una expansión asimétrica y anular en torno a la plaza mayor (Bogotá, Caracas, Lima, México, Puebla y Quito). Se amplía el Distrito Central de negocios, pasando los límites de la ciudad colonial. Se abren nuevos ejes comerciales como centros de gravedad de comercio al por menor y del sector de servicios privados. La administración pública central perdura en edificios tradicionales representativos en torno a la Plaza mayor (Gormsen, 1993). Así, los centros históricos de la ciudad de La Habana, Montevideo y Panamá están ubicados en penínsulas de reducida superficie, cada vez más alejados de las áreas de expansión urbana. A pesar de esto, hay un gran número de ciudades que respetaron las formas de construcción tradicional como: Puebla, Bogotá, Ecuador, Colombia y Blumenau.

\subsection{Estrategias de preservación del patrimonio cultural Quito, Ecuador}

\section{Antecedentes}

La fundación de la ciudad obedeció a causas estratégicas, independientemente de su topografía y ubicación, sin embargo, se observan beneficios ante los valles adyacentes, adecuados para su urbanización, componente determinante por parte de los pueblos aborígenes.

“La conquista española de los Andes septentrionales fue motivada principalmente por el rumor de que en Quito se encontraba el tesoro de Atahualpa. Se formaron dos expediciones en su búsqueda: la de Pedro de Alvarado, a través de la cordillera occidental, y la de Sebastián de Benalcázar. Fue este último el que consiguió llegar primero y quien el 6 de diciembre de 1534 fundó la ciudad de San Francisco de Quito" (Achig, 1983).

\section{Traza y morfología de la ciudad}

En Quito desde sus orígenes predomino el crecimiento lineal, relacionado a los límites topográficos y naturales, aunque como podemos ver en la figura 2, donde la traza en retícula característica de las ciudades coloniales se respetó. Podemos afirmar como resultado de esta investigación que uno de los mayores impactos urbanos que tuvo el crecimiento de la ciudad histórica de Quito fue el predominio de las relaciones capitalistas de producción de 1895 a 1910 que intervinieron de manera arbitraria a la planeación urbana de la ciudad, siendo uno de los procesos más relevantes de trasformación. No obstante, el desarrollo urbano de Quito tuvo tres periodos de importancia en cuanto a la transformación de este: el primero que duró desde la revolución liberal hasta fines de la década de los años 50.

El Plan Odriozola concertó las ideas urbanísticas europeas y norteamericanas de fines del XIX e inicios del XX, además de revalorizar las transformaciones urbanas y regionales de la sierra centro y norte desde los años veinte, con la ruptura de los patrones sociales patriarcales que controlaban a las elites, influyo en la emergencia de los sectores artesanales y obreros y la degradación de la vida social urbana. Por otra parte, el Centro histórico de Quito fue declarado patrimonio cultural de la Humanidad en 1978, y una década más tarde en el año 1988 se realiza una intervención importante que le ha llevado a ser reconocido como una experiencia de gestión urbana calificada como exitosa, derivada de la participación de actores públicos y privados a nivel nacional e internacional, gracias a un conjunto de ordenanzas promulgadas durante la alcaldía de Jacinto Jijón y Caamaño (1946-1947) que buscaban la protección del primer cuadro de la ciudad. De esta manera, se delimito espacial y conceptualmente el área histórico patrimonial, lo que actualmente el Centro Histórico de Quito (Cabrera, 2017).

\section{Instrumentos actuales de conservación del patrimonio histórico en Quito}

Actualmente, el Centro Histórico comprende más de 370 hectáreas de protección edificada y más de 230 hectáreas de protección natural (figura 3). El anillo edificado está formado por dos zonas: el núcleo central ocupado por el barrio González Suárez y el AdA formada por 14 barrios en los que predomina el tejido resi- 
Figura 2. Ciudad de Quito en 1734

Fuente: Municipio del distrito metropolitano de Quito, 2017. (Distrito Metropolitano de Quito, 2017).
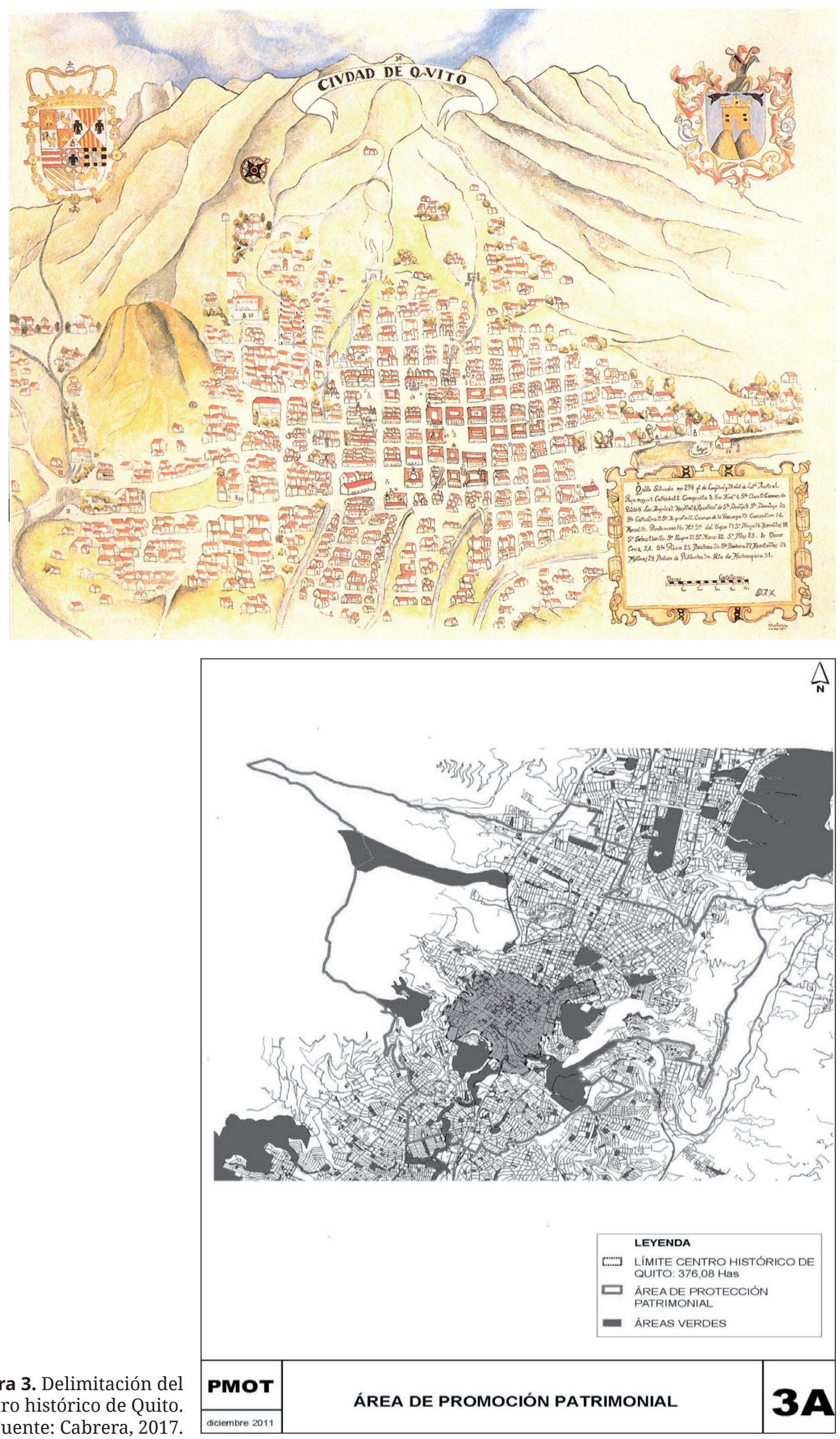

Figura 3. Delimitación del centro histórico de Quito. Fuente: Cabrera, 2017. 
dencial. Este relevante legado doméstico ameritó diversos análisis desde fines del siglo XX, aunque sólo muy recientemente se han focalizado propuestas con énfasis en los usuarios, a través de desarrollos específicos del IMP (Sánchez \& Woolfson, 2016, 31).

Es importante destacar que el centro histórico de Quito es el menos alterado y mejor conservado de América. Tiene alrededor de 130 edificaciones monumentales (donde se aloja una gran diversidad de arte pictórico y escultórico, principalmente de carácter religioso inspirado en una multifacética gama de escuelas y estilos) y cinco mil inmuebles registrados en el inventario municipal de bienes patrimoniales. Pero el debate cultural en defensa del patrimonio alcanzó su cúspide cuando en 1967 se promulgaron las Normas de Quito, para la protección del Patrimonio Cultural y ese mismo año el municipio dictó la Ordenanza del Centro Histórico, delimitando el área a proteger, constituyéndose en la primera ordenanza vigente en Latinoamérica, de protección de una zona histórica (Zamorano, 1991). Sin embargo, el Centro Histórico comenzaba a desmoronarse; muchos de los antiguos y acaudalados propietarios se habían marchado para ubicarse en la nueva ciudad jardín. Las antiguas casonas se comenzaron a arrendar, con carencias de los más elementales servicios y adónde habían llegado gran parte de inmigrantes de todas las regiones del país y las clases menos favorecidas de la sociedad. Muchas de estas casas posteriormente fueron adquiridas por los nuevos comerciantes, pero ante la falta de una cultura de valoración por estos artísticos inmuebles, se realizaron transformaciones y subutilizaciones que, terminaron por alterar importantes segmentos arquitectónicos. Otros en cambio, optaron por destruir los inmuebles para construir nuevos edificios (Mertins, 2006), en la tabla 1 se muestran los objetivos de cada acción implementada para el Centro Histórico de la Ciudad de Quito.

Tabla 1. Acciones realizadas para el Centro Histórico de la Ciudad de Quito, Ecuador.

\begin{tabular}{|c|c|c|}
\hline AÑO & $\begin{array}{c}\text { Acciones, Planes y Programas de inter- } \\
\text { vención en Quito }\end{array}$ & Objetivo \\
\hline 1967 & Plan Director de Urbanismo de Quito & $\begin{array}{l}\text { Incentivar una planificación concebida entonces como } \\
\text { "la solución al problema urbano" Quito, al igual que } \\
\text { otras ciudades de la región, por medio de un crecimiento } \\
\text { pronunciado. El Plan aparecía en medio de problemas } \\
\text { producidos por el crecimiento poblacional y la necesidad de } \\
\text { control y legislación. }\end{array}$ \\
\hline 1973-199 & $\begin{array}{l}\text { Plan Quito y su área metropolitana, Plan } \\
\text { Director }\end{array}$ & $\begin{array}{l}\text { Plantear la organización distrital para la ciudad y su } \\
\text { microrregión que se traduce en una propuesta de } \\
\text { desconcentración y expansión macro regional como soporte } \\
\text { para racionalizar su estructura territorial. }\end{array}$ \\
\hline 1989-1991 & $\begin{array}{l}\text { Plan de Rehabilitación Integral de las } \\
\text { Áreas Históricas de Quito }\end{array}$ & $\begin{array}{l}\text { Desarrollar en el plan de Rehabilitación Integral de las Áreas } \\
\text { Históricas dos procesos para poder llevar en función sus } \\
\text { objetivos, lo cual fue elaborar sus propuestas y ejecutarlas } \\
\text { en dos partes una sectorial y el otro terrestre, con el fin de } \\
\text { mejorar el área histórica. }\end{array}$ \\
\hline $1997-2000$ & $\begin{array}{l}\text { Proyecto de desarrollo social del centro } \\
\text { histórico }\end{array}$ & $\begin{array}{l}\text { Establecer las relaciones entre lo económico, social y la } \\
\text { gestión de la Empresa del centro histórico. Pueden ser } \\
\text { analizadas desde dos puntos de vista, el primero, el de los } \\
\text { efectos que las circunstancias económicas y sociales han } \\
\text { tenido sobre la gestión de la economía del centro histórico } \\
\text { y el segundo los efectos que la gestión de la economía } \\
\text { del centro histórico ha tenido sobre la dinámica social y } \\
\text { económica del centro. }\end{array}$ \\
\hline 2004 & $\begin{array}{l}\text { El Plan espacial del Centro Histórico de } \\
\text { Quito }\end{array}$ & $\begin{array}{l}\text { Lograr que el centro histórico de Quito se afiance como un } \\
\text { espacio urbano emblemático, singular e irrepetible mediante } \\
\text { el Plan espacial del Centro Histórico de Quito. }\end{array}$ \\
\hline
\end{tabular}




\begin{tabular}{|c|c|c|}
\hline AÑO & $\begin{array}{c}\text { Acciones, Planes y Programas de inter- } \\
\text { vención en Quito }\end{array}$ & Objetivo \\
\hline 2004 & Plan Estratégico del DMQ & $\begin{array}{l}\text { Lograr cuatro ejes fundamentales: político, económico, } \\
\text { social y territorial; éste, mediante siete programas. Basada } \\
\text { en un modelo de ciudad deseable, "La ciudad sostenible } \\
\text { social, económica, política y ambientalmente, es aquella } \\
\text { que es compacta y densa, con continuidad formal; es } \\
\text { multifuncional, heterogénea y diversa en toda su extensión" } \\
\text { (Moncayo, 2004: 6), contiene planes, programas y proyectos } \\
\text { en función de estos cuatro ejes que plantea el plan } \\
\text { estratégico. }\end{array}$ \\
\hline
\end{tabular}

Fuente: Elaboración propia a partir de revisión de planes y programas oficiales en páginas web 2019.

\subsection{Estrategias de preservación del patrimonio cultural La Habana, Cuba}

\section{Antecedentes}

Después del descubrimiento de la isla de cuba que en sus inicios la nombraron isla Juana, se comenzarían los trabajos de colonización fundando siete villas coloniales cubanas, Nuestra Señora de la Asunción de Baracoa en 1511 (Baracoa); San Salvador de Bayamo en 1513 (Bayamo); la Villa de la Santísima Trinidad (Trinidad) y Santa María del Puerto del Príncipe (Camagüey), ambas a principios de 1514; Sancti Spíritus, a mediados de 1514; Santiago de Cuba, en 1515; y, finalmente, San Cristóbal de La Habana 1515, aunque en una ubicación situada al sur de la localización actual de La Habana, por lo que se considera que se fundó en 1519 por el conquistador español Diego Vázquez La Habana fue la sexta ciudad fundada por la corona española en la isla de Cuba llamada anteriormente San Cristóbal de la Habana, la ciudad tuvo dos asentamientos distintos entre 1514 y 1519 antes de su fundación (figura 4).

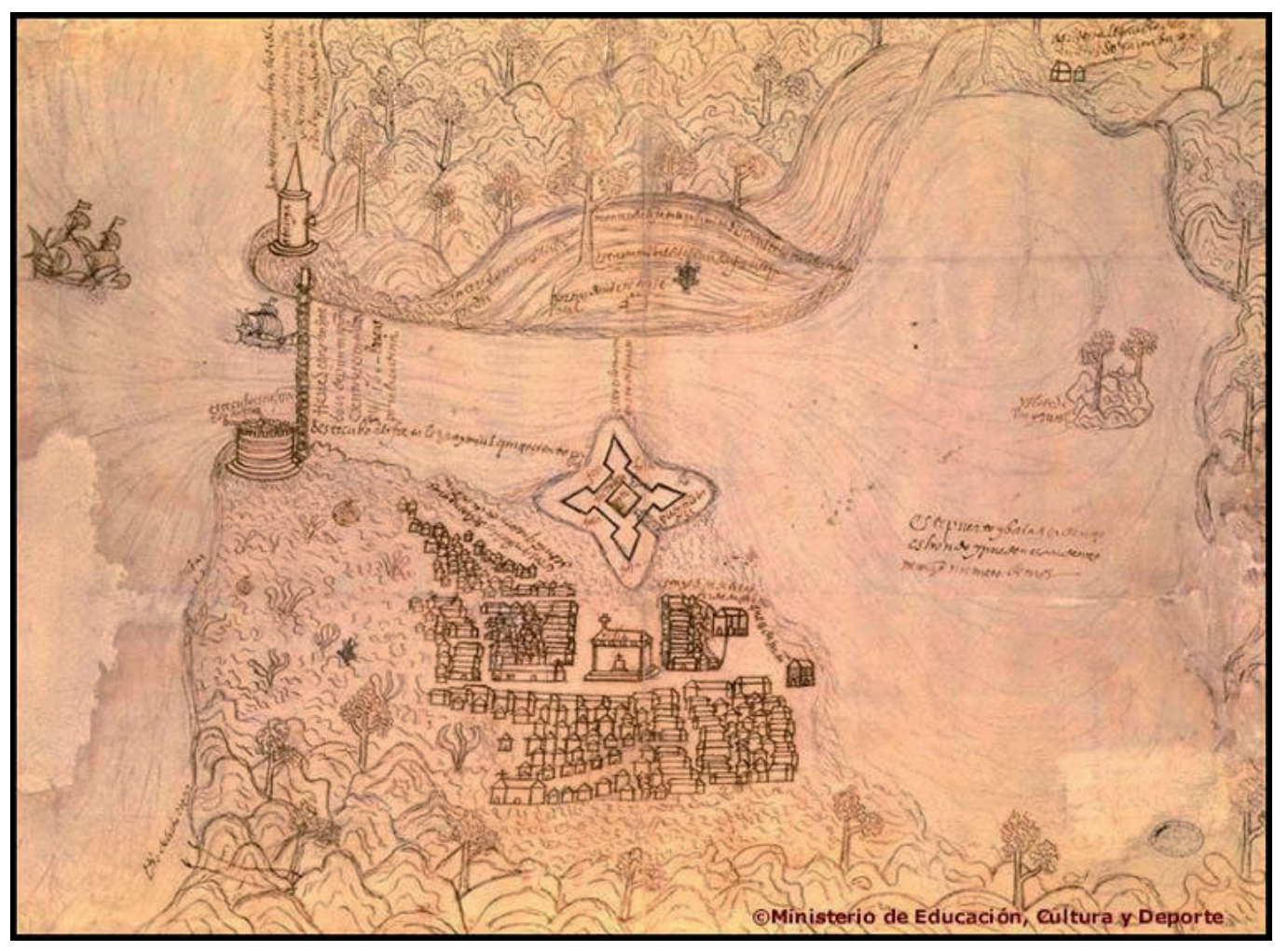

Figura 4. Uno de los Primeros planos de La Habana elaborado en el siglo XVI. Fuente: Blasco, 2016. 


\section{Traza y morfología de la ciudad}

La Habana es una ciudad ecléctica, aunque al pasar de los años ha absorbido influencias varias (americanas, europeas, africanas y asiáticas), la traza de esta ciudad fue desarrollada con base a referencias extraídas de las ciudades peninsulares medievales (figura 5). Como se ha mencionado en el apartado de traza urbana y planeación de las ciudades latinoamericanas, la traza más común era la de damero, aunque se logró formar una cuadricula casi perfecta es evidente que La Habana no es precisamente una ciudad colonial canónica.

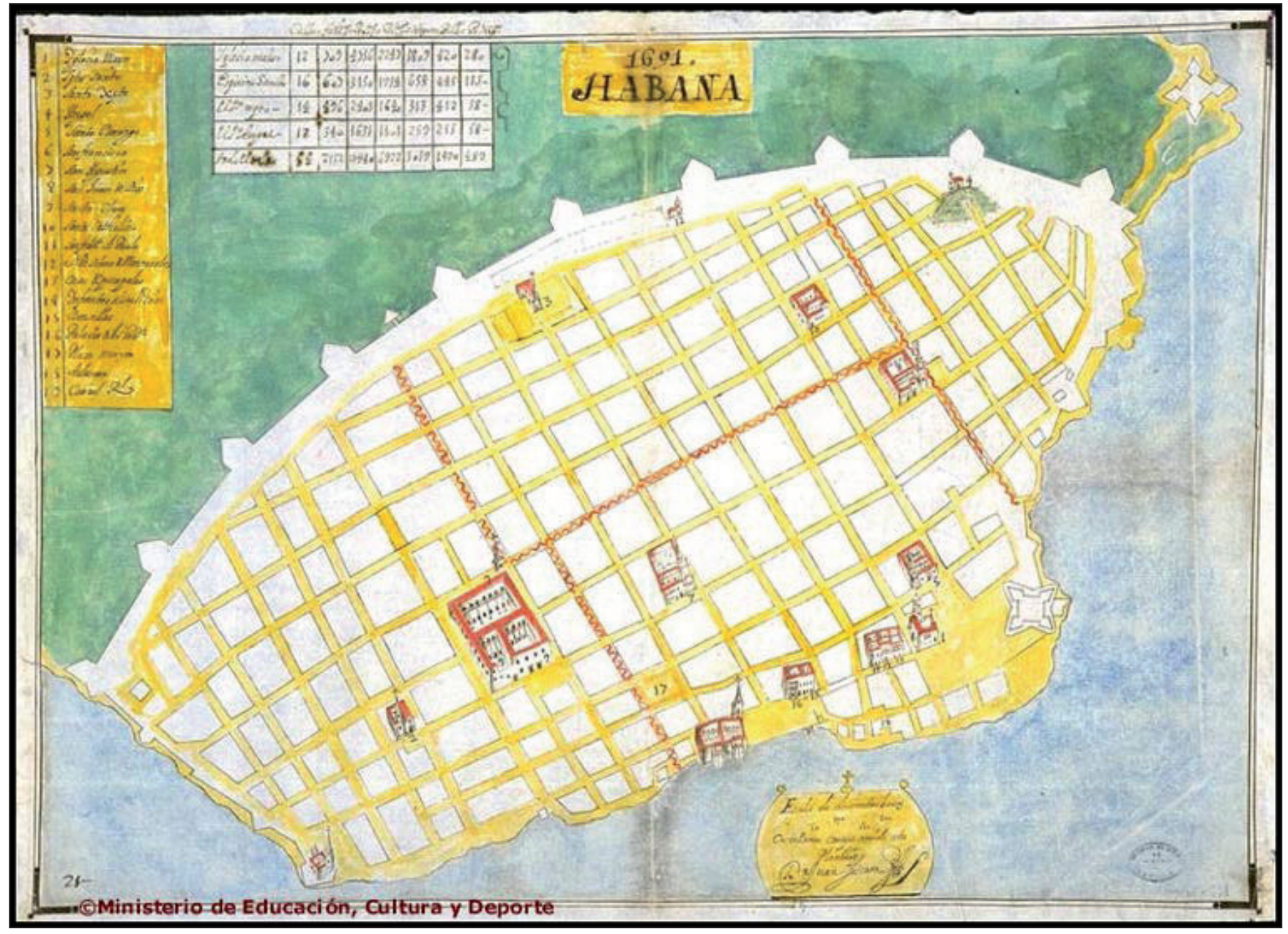

Figura 5. La Habana en 1691, plano de Juan Siscara. Fuente: Blasco, 2016.

Es importante mencionar que existieron dos hechos que son de gran importancia para el rumbo de la ciudad, el primero fue la instauración de un puerto único, que concentraría toda la flota de indias lo que lo colocaría como uno de los más importantes e impactaría satisfactoriamente a su economía, el segundo hecho fue la fortificación de la ciudad, esto como consecuencia del hecho anterior. Se levantaron las primeras edificaciones (castillo del Morro, catillo de la punta, castillo de la real fuerza) y se complementó con la construcción de murallas cuyo objetivo era la protección tanto de la ciudad como del puerto, este sistema se complementaría con nuevos aditamentos como el fuerte de Santa Dorotea de la Luna de la Chorrera cuya función era la de evitar que barcos enemigos se abastecieran de agua dulce además de controlar el acceso a la bahía. En sus inicios la ciudad contaba con cuatro espacios principales cada uno de gran importancia, la plaza de armas que fue en la época colonial un referente de vida oficial y publica de la Habana, la plaza de la catedral que se dirigía hacia lo más religioso, la plaza Nueva/vieja, en función al comercio, la plaza de San Francisco vinculada a los muelles y el puerto. 


\section{Instrumentos actuales de conservación del patrimonio histórico en la Habana}

Es así como surge la urgencia de la protección de edificios y monumentos históricos que conforman el casco histórico de La Habana, así como la importancia de la divulgación de la su cultura nacional e internacionalmente, uno de los mayores logros de fue ser declarado patrimonio cultural de la humanidad por la UNESCO en 1982. "El Centro Histórico y su Sistema de Fortificaciones Coloniales de la ciudad de la Habana fundada en 1519, son considerados desde 1978 Monumento Nacional y fueron declarados por la UNESCO Patrimonio Mundial el año 1982. La Oficina del Historiador de la Ciudad de La Habana (OHCH) fue responsabilizada, en la más alta dirección del país con la restauración de La Habana Vieja, primero bajo un esquema de asignación financiera central; posteriormente, y bajo el escenario de una gravísima crisis económica debida a la caída del bloque socialista, bajo un concepto de descentralización económica que ha garantizado la dinamización de una economía local que reinvierte en la zona lo que ella es capaz de producir; "a este esquema público se suma más recientemente el potencial que supone el crecimiento de un sector privado de una escala apropiada (PYMES) y el establecimiento de alianzas estratégicas entre ambos sectores, para acelerar la consecución de los objetivos de prosperidad y equidad que garantizan el modelo" (Rodríguez, 2016, 46).

En 1603 se modifican parte de los primeros trazos y se alinean las fachadas que, gradualmente conformaron la retícula urbana de forma compacta con calles angostas y manzanas o cuadras irregulares. Hacia el siglo XVII se en la ciudad tanto sus cinco plazas, como el sistema de plazuelas que la diferencian en el país de otros centros históricos. Sus edificaciones adoptaron "el régimen de medianería que, juntamente con el patio interior, constituyen elementos básicos de las tipologías arquitectónicas del centro histórico" (Arjona, 1982). Otra de las transformaciones más notables durante el año 1863 es la eliminación de la muralla, dando paso a la unificación física de la nueva ciudad con el histórico casco urbano. En su interior tuvo lugar un trazado compacto, que dio lugar a una urbanización colosal denominada "Reparto Las Murallas". Donde se reunieron "edificios públicos, teatros, hoteles, residencias fastuosas e inmuebles con funciones productivas, comerciales y administrativas, vinculadas al capital económico y financiero peninsular de la época" (Venegas, 1990). Posteriormente durante el siglo XVIII, una vez que el crecimiento de la Habana había desbordado las murallas erigidas entre 1674 y 1740 da como resultado el origen de los al oeste y suroeste de los barrios extramuros (Gavira, 1983) (figura 6).

Para el siglo XIX aumentan los avances técnicos en planeación urbana introducidos en la ciudad. De esta manera, el paisaje de extramuros actual se perfecciona por Jean Claude Nicolás Forestier en el Plan de Embellecimiento y Ensanche, en la década de 1920: el Parque Central, el Palacio Presidencial, el Paseo del Prado, el Parque de la Fraternidad, y el Capitolio Nacional, la Avenida del Puerto y un sistema de espacios públicos de muy alta calidad urbanística (figura 7).

En 1959, se elaboró el Plan Director de La Habana donde se establecieron las diferentes zonas de desarrollo: vivienda, producción, transporte y red vial, áreas verdes, estudios demográficos y sociales, redes técnicas y de protección ambiental. En este Plan se constituyeron diferentes zonas de desarrollo, como son: producción, vivienda, red vial y transporte, áreas verdes, estudios sociales y demográficos. Posteriormente, gracias a la preservación de su conjunto edificado, el paisaje del entorno a sus espacios públicos y ambientes enriquecidos y a la trama histórica de la ciudad, se registra como Patrimonio Cultural de la humanidad en 1982. Adicionalmente, durante las últimas décadas, sus actividades tradicionales, se han ido fortaleciendo a causa de su diversa vida cultural, sin mencionar, un marcado carácter residencial. En el decreto de Ley No. 143, el Consejo del Estado define el Centro histórico de la ciudad de La Habana como "zona prioritaria para la conservación". Más tarde en 1955, el Centro Histórico de la ciudad a través del acuerdo No. 2951 se otorga la condición de "Zona de Alta significación para el turismo".

En 1982 se reconoce como Patrimonio Cultural de la Humanidad sustentado, por una parte, en la preservación de un valioso conjunto edificado y, por otra, en el tejido histórico de sus calles, espacios públicos y ambientes enriquecidos por el atractivo paisaje circundante. A estos valores se suma un marcado carácter residencial y la continuidad de actividades tradicionales, fortalecidas en los últimos tiempos con el despliegue de una variada vida cultural (Glaeser, 2011). En 1993 se promulga el Decreto Ley no 143 del Consejo de Estado y se establece el Centro Histórico de la ciudad de La Habana como zona prioritaria para la conserva- 


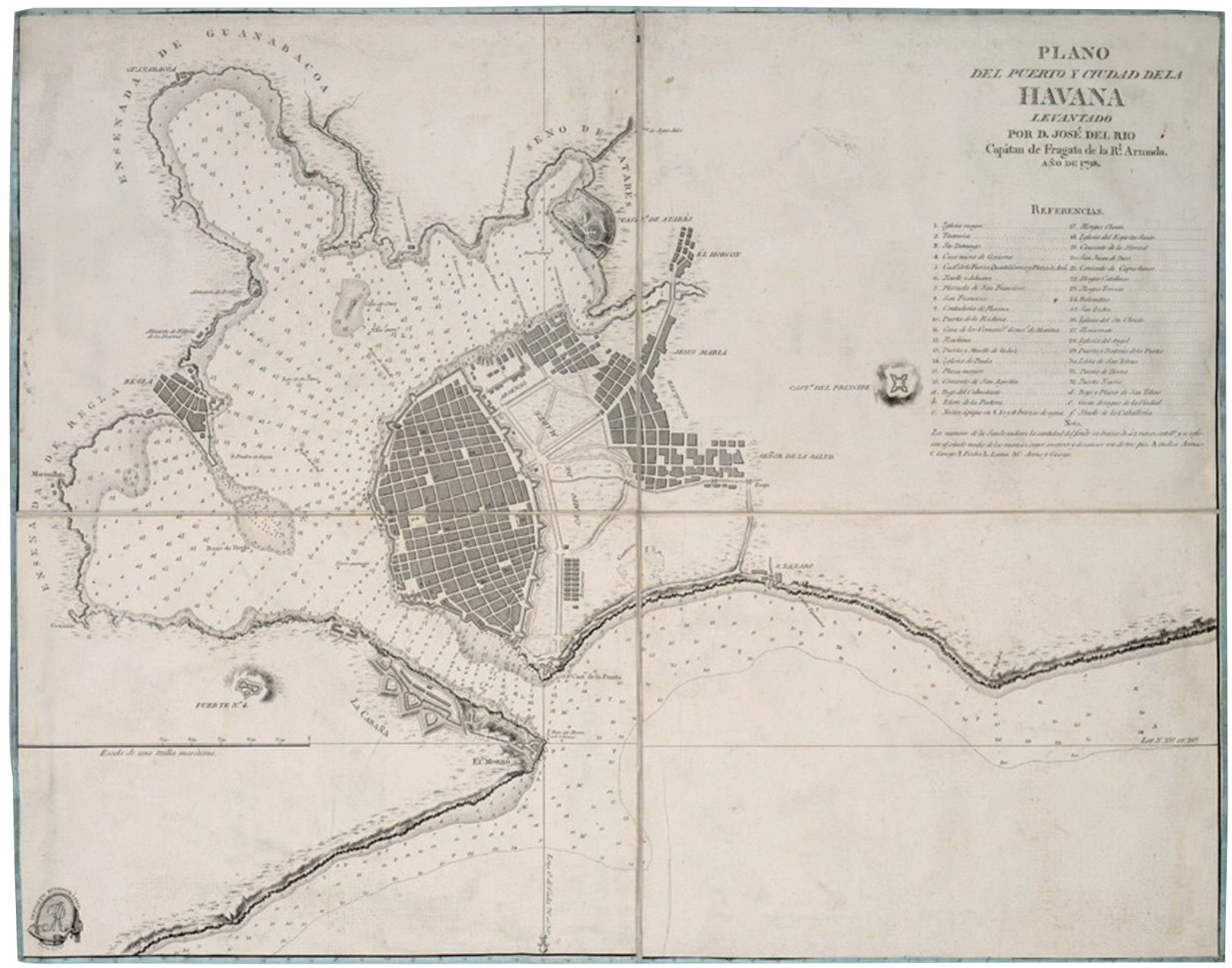

Figura 6. Plano del Puerto y la ciudad de La Habana. Fuente: Armada, 1798.

ción. En el Acuerdo N. ${ }^{\circ} 2951$ del Consejo de Ministros de 1995 se otorga al Centro Histórico la condición de Zona de Alta Significación para el Turismo.

“El modelo de gestión de desarrollo integral, que se aplica desde 1994 ha facilitado destinar los ingresos provenientes de la explotación de los recursos culturales, turísticos, terciarios e inmobiliarios, y de impuestos especiales, al fomento progresivo de inversiones, fundamentalmente dirigidas a la recuperación de edificios de valor patrimonial y espacios públicos, destacando intervenciones con fines culturales, turísticos, viviendas, obras sociales, plazas y parques, además del desarrollo de otros proyectos que elevan la calidad de vida de los residentes. Durante las dos últimas décadas se recuperaron diez veces más inmuebles que en los quince años de trabajo que precedieron a la aplicación del nuevo modelo de gestión descentralizada; se crearon más de 13.000 puestos de trabajo directos y unos 2.000 indirectos, estando el $50 \%$ de los mismos ocupados por residentes locales o de municipios aledaños" (Rodríguez, 2016, 46).

Algunas de las acciones que le implementaron en el centro histórico de la Habana Cuba se muestran en la tabla 2.

\subsection{Estrategias de preservación del patrimonio cultural Puebla, México}

\section{Antecedentes}

La ciudad de Puebla de los Ángeles se fundó el 16 de abril de 1531, "se sitúa en el Valle de Cuetlaxcoapan al pie del volcán Popocatépetl entre los límites de los dominios indígenas de Tlaxcala, Cholula y Cuauhtinchan, 


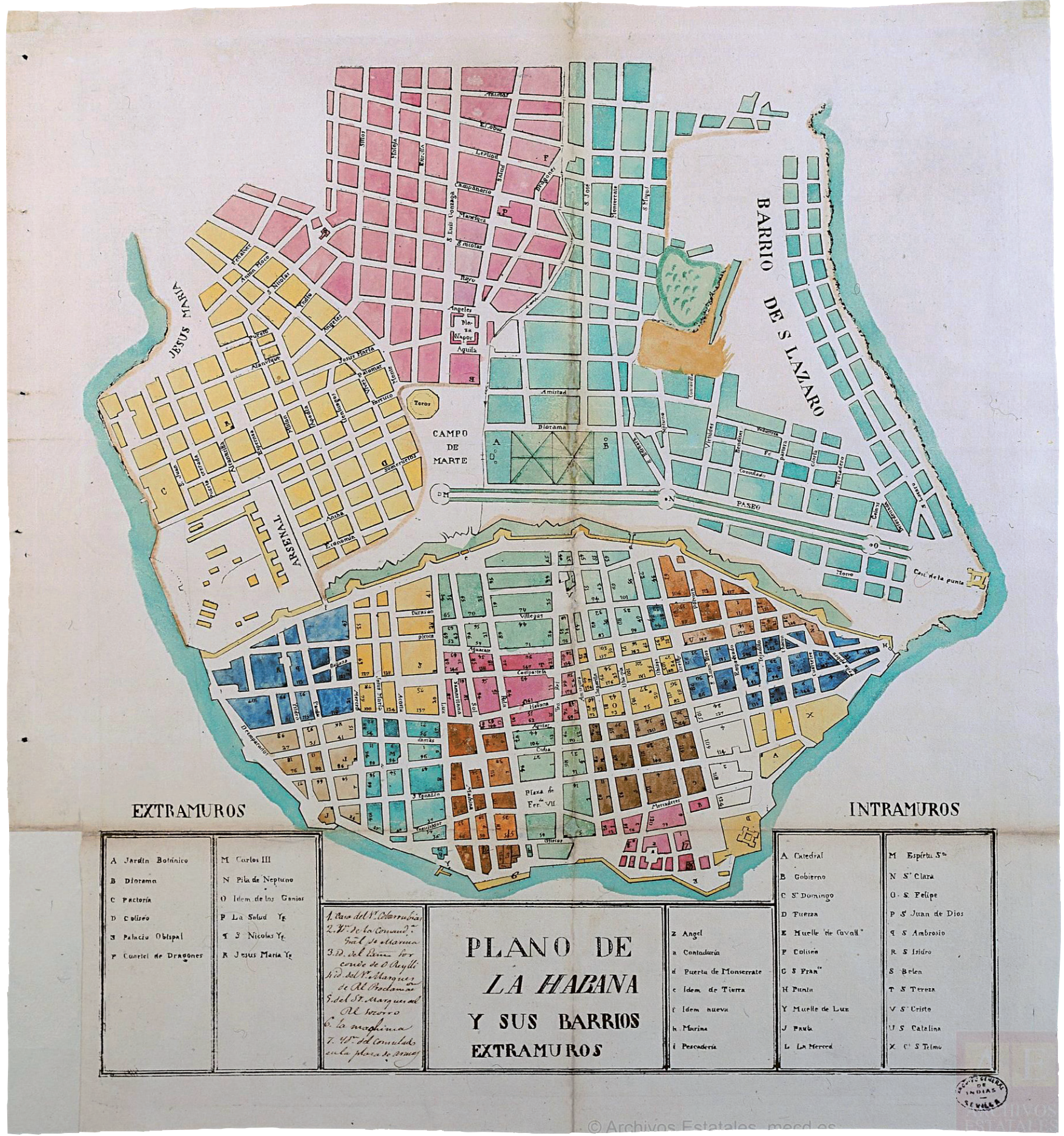

Figura 7. Plano de la Habana y sus barrios extramuros, 1829. Fuente: Oficina del Historiador, 2011.

siguiendo las recomendaciones reales de España para no tomar posesión de territorios indígenas (Cruz, Perez, Torralba, \& y Bonilla, 2017) (figura 8).

Los investigadores que han estudiado el origen de la fundación de la Ciudad de Puebla afirman que nace como un experimento social utópico, que resulta de la transición de una sociedad noble formada por conquistadores hacia una sociedad colonial urbana integrada por agricultores, ganaderos y comerciantes, alejada de las comunidades indígenas con la finalidad de evadir su mano de obra (González, 1993). De esta forma los indios estarían a salvo de los abusos de los exploradores y los españoles podrían sobrevivir por sus propios medios. Objetivos claros y una voluntad política en la que se involucran autoridades como: el 
Tabla 2. Acciones realizadas para el Centro Histórico de la Ciudad de la Habana Vieja.

\begin{tabular}{|c|c|c|}
\hline AÑO & $\begin{array}{c}\text { Acciones, Planes y Programas de interven- } \\
\text { ción en la Habana }\end{array}$ & Objetivo \\
\hline 1983 & $\begin{array}{l}\text { Plan de acción para la conservación y res- } \\
\text { tauración del centro histórico de La Habana } \\
\text { Vieja y su sistema de fortificaciones }\end{array}$ & $\begin{array}{l}\text { Realizar una intervención en el centro histórico de la } \\
\text { Habana Cuba, tomando como prioridad el turismo que } \\
\text { llega en esta zona, de acuerdo con el plan este objetivo } \\
\text { se llevara a cabo mediante una remodelación y restau- } \\
\text { ración de todo el patrimonio histórico, conservando las } \\
\text { zonas con mayor valor histórico y cultural. Este proyecto } \\
\text { se difundió de manera nacional e internacional, dando a } \\
\text { conocer sus valores culturales, sociales e históricos de la } \\
\text { Habana Cuba. }\end{array}$ \\
\hline 1983 & $\begin{array}{l}\text { Campaña Internacional para la Salvaguarda } \\
\text { de la Plaza Vieja de la ciudad de la Habana }\end{array}$ & $\begin{array}{l}\text { Conservar el Centro Histórico mediante diversas estra- } \\
\text { tegias, como las medidas legislativas, los planes para } \\
\text { su recuperación en cuestiones de vivienda e hitos con } \\
\text { algún valor cultural, en las cuales se darían a conocer } \\
\text { con gran éxito a nivel internacional. Con el apoyo finan- } \\
\text { ciero de la UNESCO para su sustento, dando a conocer } \\
\text { la Plaza Vieja de la Habana internacionalmente lo cual } \\
\text { logro grandes proyectos que se organizaban de todo } \\
\text { Latino América. }\end{array}$ \\
\hline 1998 & $\begin{array}{l}\text { Desafío de una utopía una estrategia inte- } \\
\text { gral para la gestión de salvaguarda de la } \\
\text { Habana Veja }\end{array}$ & $\begin{array}{l}\text { Establecer una estrategia para la gestión de salvaguarda } \\
\text { de la Habana, como apoyo metodológico el cual habla } \\
\text { acerca de la elaboración del plan especial integral PEDI } \\
\text { para llevar a cabo una gestión, coordinación, desarrollo } \\
\text { implementación y perfección de diversos mecanismos } \\
\text { que ayudaría al desarrollo del centro histórico. Mediante } \\
\text { diversos puntos específicos para su recuperación como el } \\
\text { derrame económico que genera el turismo en esta zona, } \\
\text { con la difusión internacional, así como la cooperación para } \\
\text { su mejora. }\end{array}$ \\
\hline 2001 & $\begin{array}{l}\text { Plan Estratégico del Centro Histórico. Plan } \\
\text { Maestro- Oficial del Historiador }\end{array}$ & $\begin{array}{l}\text { Crear el Plan Maestro y las Oficinas del Historiador, en- } \\
\text { focado en la conserva con, restauración y recuperación } \\
\text { del centro histórico mediante diversos objetivos, pero } \\
\text { siempre teniendo al turismo como primera potencia eco- } \\
\text { nómica. }\end{array}$ \\
\hline $2016-2030$ & $\begin{array}{l}\text { Plan Especial de Desarrollo Integral La Ha- } \\
\text { bana Vieja Centro Histórico (PEDI) }\end{array}$ & $\begin{array}{l}\text { Considerar el ámbito urbano, arquitectónico, o económi- } \\
\text { co, así como también diversos puntos en el ámbito social. } \\
\text { Se pretende tener una conservación, recuperación y } \\
\text { remodelación del centro histórico, teniendo como objetivo } \\
\text { plazas específicas para potencializar más en turismo, pero } \\
\text { siempre conservando su cultura y valores históricos que } \\
\text { se ofrecen en ella. Este proyecto se ve proyectado haya } \\
\text { el año } 2030 \text {, aunque se comienza primero que el plan } \\
\text { Estratégico del centro Histórico y se publica en el } 2016 \text {, su } \\
\text { visión es hasta el año } 2030 \text {. }\end{array}$ \\
\hline
\end{tabular}

Fuente: Elaboración propia a partir de revisión de planes y programas oficiales en páginas web 2019.

obispo de Tlaxcala, fray Julián Garcés (de la orden de Santo Domingo), los misioneros franciscanos (en 1524 Hernán Cortes recibió la primera misión de religiosos franciscanos de doce sacerdotes y un lego entre los que se encontraba Fray Toribio de Benavente conocido como Motolinía) y la Primera Audiencia con el Aval Real representada por Juan de Salmerón, Vasco de Quiroga y Alonso Maldonadoue aunaron esfuerzos para fundar la ciudad. 


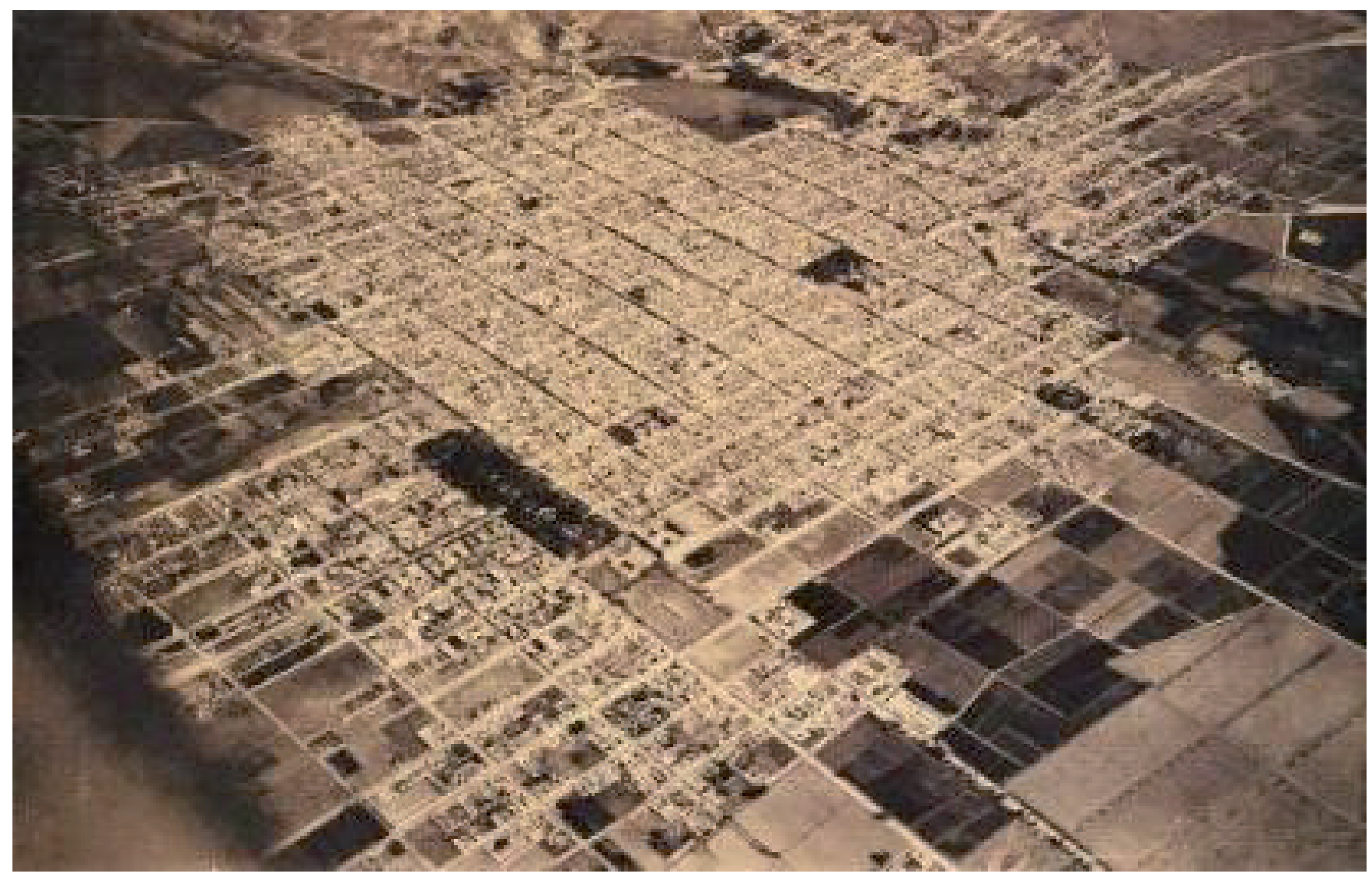

Figura 8. Panorámica aérea de la ciudad de Puebla entre los años de 1910 y 1920. Fuente: Sanz, 2008.

\section{Traza y morfología de la ciudad}

El trazado urbano del casco histórico es regular de tipo damero perteneciente a un modelo clásico como lo vimos en el apartado de la traza urbana y planeación de las ciudades en América Latina. Las características más sobresalientes de su morfología es una malla homogénea, con manzanas rectangulares de 100 por 200 varas. (91 por 182 metros.); cada manzana se dividía en 8 cuadrados de 50 por 50 varas. Las calles miden 14 varas (13.20 metros). La plaza mayor se localiza en el centro de esta traza. Del vértice noroeste parten ejes cartesianos, que forman las dos avenidas principales dividiendo a la ciudad en cuatro sectores. Alrededor de esta plaza se levantan los principales edificios religiosos y de gobierno. En tres de los lados que circundan a la plaza mayor, se construyeron arcadas.

En la periferia se ubican los molinos, haciendas, templos y un entorno de ejidos organizado, provocando que lo rural penetra en lo urbano entre la última década del siglo XIX y la primera década del siglo XX, el contenido arquitectónico de la ciudad central se enriqueció con la construcción y/o remodelación de algunos edificios incluida la modernización de infraestructuras, a manera de ejemplo, se encuentra el Palacio Municipal, y el mercado La Victoria. Sin embargo, en el caso de los barrios estos tuvieron trayectorias más lentas como sucedió con los barrios del Alto y de Analco que se ubican al oriente donde se alojó la reciente industria y reforzó la condición social trabajadora de estos territorios. Consecutivamente en la primera mitad del siglo XX, comienzan a surgir colonias y fraccionamientos que se expanden en la ciudad produciendo un fenómeno de descentralización de servicios que provoca que el Centro Histórico desde entonces se convierta en un receptor de subsistemas de equipamiento como educación y comercio básicamente. No obstante, debido al grado de deterioro que muestra el patrimonio edificado principalmente en los barrios del Centro Histórico en este siglo XXI, es indispensable la creación de políticas dirigidas a recuperar los inmuebles a través de un proyecto de rehabilitación integral que contemple acciones de mejoramiento como la restauración y conservación (figura 9). 


\section{Instrumentos actuales de conservación del patrimonio histórico en Puebla}

A lo largo del desarrollo de la ciudad de Puebla, se han creado políticas públicas que tienen como objetivo la protección del patrimonio cultural como planes y programas, como el plan de manejo del centro histórico, en el cual se realiza una serie de análisis y se generan soluciones a algunas amenazas que enfrenta el patrimonio cultural. Durante el proceso de la investigación se identificaron algunas acciones encaminadas a la conservación del centro histórico y su patrimonio, como lo es la creación del Consejo del Centro Histórico de la ciudad de Puebla responsable de proteger, preservar, custodiar y mejorar la zona de monumentos, además del establecimiento de una delimitación de la zona, la cual es utilizada hasta la actualidad (figura 10).

Asimismo, para el centro histórico se crearon algunos programas como el, Programa Operativo para la Reutilización y Revitalización del Centro Histórico en 1992 que trataba de establecer lineamientos para el rescate y la conservación del Centro Histórico de Puebla, de igual forma el Programa de Desarrollo Urbano de la ciudad de Puebla que establece el marco legal referente a patrimonio y desarrollo de proyectos en el centro histórico.

Con programas y acciones como las anteriores se creó el Plan Emergente del Centro Histórico para la recuperación a través de actividades de dignificación de su imagen urbana como, el repoblamiento aprovechando el patrimonio construido, adecuación de inmuebles compatibles con usos de vivienda, conservación, restauración y adecuación de inmuebles históricos con un alto valor arquitectónico y cultural, reactivación económica y social del centro histórico (tabla 3).

Puebla, es una ciudad con una gran riqueza patrimonial y este debe ser protegido al considerarse como espacio importante para la sociedad poblana, recientemente se han desarrollado proyectos de mejoramiento de la zona. Uno de los últimos instrumentos de planeación para el centro histórico, es el programa parcial de desarrollo urbano sustentable del centro histórico del municipio de Puebla, el cual establece lo siguiente:

“El, tiene como propósito actualizar la estrategia, políticas y normas de desarrollo urbano de esta zona. En este ámbito territorial se inscribe la necesidad de contar con un instrumento vigente y en operación, que responda a las nuevas circunstancias que permita ordenar y regular los aprovechamientos territoriales con una visión de sustentabilidad a largo plazo, además de proporcionar certidumbre a las inversiones pública, privada y social en una de las áreas estratégicas más importantes del centro urbano metropolitano" (Gobierno Municipal, 2015).

Para poder salvaguardar el centro histórico el gobierno de la ciudad se piensa que es necesaria la implementación de la vivienda en este y al mismo tiempo se empezó a pensar en un transporte que le permitiera 
a cualquier persona el poder acceder al centro. Sin embargo, estas ideas aun no logran una revalorización de parte de los poblanos, por ello necesita un proyecto innovador o que por lo menos resuelvan en parte el problema de deterioró que sufre el primer cuadro de la ciudad. La ciudad de Puebla no debe considerarse sólo como, edificaciones valiosas, sino más bien se debe concebir como un conjunto de espacios interrelacionados los cuales cuentan la historia de la ciudad. Lo que nos permite concluir que el Centro Histórico es un espacio público donde solo algunos proyectos proporcionan alguna ventaja para la ciudad y los pobla-

Tabla 3. Acciones realizadas para el Centro Histórico de la Ciudad de Puebla.

\begin{tabular}{|c|c|c|}
\hline AÑO & $\begin{array}{c}\text { Acciones, Planes y Programas de intervención en } \\
\text { Puebla }\end{array}$ & Objetivo \\
\hline 1987 & $\begin{array}{l}\text { Declaración del Centro Histórico de Puebla como } \\
\text { Patrimonio Cultural de la Humanidad (UNESCO) }\end{array}$ & $\begin{array}{l}\text { Preservar el legado de monumentos y sitios de } \\
\text { gran riqueza natural y cultural, propiedad de toda la } \\
\text { humanidad. }\end{array}$ \\
\hline 1991 & $\begin{array}{l}\text { Creación del Consejo del Centro Histórico de la ciu- } \\
\text { dad de Puebla. }\end{array}$ & $\begin{array}{l}\text { Ejecutar obras de restauración y mantenimiento } \\
\text { para proteger, conservar y mejorar la zona histórica } \\
\text { y el patrimonio monumental de la ciudad de Puebla. }\end{array}$ \\
\hline 1992 & $\begin{array}{l}\text { Programa Operativo para la Reutilización y Revitali- } \\
\text { zación del Centro Histórico Puebla }\end{array}$ & $\begin{array}{l}\text { Establecer lineamientos para el rescate y la conser- } \\
\text { vación del Centro Histórico de Puebla. }\end{array}$ \\
\hline 1993 & $\begin{array}{l}\text { Programa Parcial de Desarrollo Urbano, Mejoramien- } \\
\text { to, Conservación e Integración del Paseo del Río de } \\
\text { San Francisco. }\end{array}$ & $\begin{array}{l}\text { Sentar las bases para transformar la Ciudad de Pue- } \\
\text { bla a partir de la creación de una zona turística de } \\
\text { primer orden internacional y de gran impacto urba- } \\
\text { no, que sirva como detonador económico y social. }\end{array}$ \\
\hline 1993 & Declaratoria de Utilidad Pública del Programa Parcial. & $\begin{array}{l}\text { Hacer públicos los actos que incidan en el patrimo- } \\
\text { nio inmobiliario, así como la Viabilidad del Programa } \\
\text { Parcial y, por tanto, las adquisiciones y expropiacio- } \\
\text { nes requeridas. }\end{array}$ \\
\hline 1993 & Creación del Fideicomiso del Paseo del San Francisco. & $\begin{array}{l}\text { Preparar la realización de las acciones señaladas en } \\
\text { el Programa Parcial de Desarrollo Urbano, Mejora- } \\
\text { miento, Conservación e Integración del Paseo del Río } \\
\text { de San Francisco. }\end{array}$ \\
\hline 1994 & $\begin{array}{l}\text { Programa Parcial de Desarrollo Urbano y Conserva- } \\
\text { ción del Centro Histórico de la ciudad de Puebla. }\end{array}$ & $\begin{array}{l}\text { Rescatar y conservar el patrimonio urbano-arquitec- } \\
\text { tónico de la Zona Monumental de la ciudad a través } \\
\text { de su revitalización urbana. }\end{array}$ \\
\hline 1996 & $\begin{array}{l}\text { Plan de Conservación y Ordenamiento Urbano Arqui- } \\
\text { tectónico del Paseo del Río de San Francisco. }\end{array}$ & $\begin{array}{l}\text { Integrar espacios religiosos, áreas verdes, zonas } \\
\text { comerciales, culturales y de recreación, hoteles } \\
\text { restaurantes, equipamiento urbano y un centro de } \\
\text { convenciones. }\end{array}$ \\
\hline 2001 & Plan Maestro del Paseo del Río de San Francisco. & $\begin{array}{l}\text { Definir las políticas y lineamientos a seguir por parte } \\
\text { de los proyectistas de las empresas que intervinieron } \\
\text { en la Zona histórica del Paso del Río San Francisco. }\end{array}$ \\
\hline 2015 & $\begin{array}{l}\text { Programa Parcial de Desarrollo Urbano Sustentable } \\
\text { del Centro Histórico del Municipio de Puebla. }\end{array}$ & $\begin{array}{l}\text { Actualizar la estrategia, las políticas y las normas de } \\
\text { desarrollo urbano de la Zona Monumental a través } \\
\text { de un instrumento vigente y en operación. }\end{array}$ \\
\hline 2015 & $\begin{array}{l}\text { Plan de Manejo del Programa Parcial del Centro } \\
\text { Histórico. }\end{array}$ & $\begin{array}{l}\text { Canalizar la acción del sector público y privado y } \\
\text { de la sociedad en general a un mayor compromiso } \\
\text { y participación en la conservación y rehabilitación, } \\
\text { dirigida hacia un desarrollo sustentable del patrimo- } \\
\text { nio cultural. }\end{array}$ \\
\hline
\end{tabular}

Fuente: Ramírez Rosete, Basilio Calderón, \& Milián Ávila, 2017. 
dores, ya que en algunos casos los instrumentos de conservación que permiten la integración de proyectos turísticos al centro histórico afectan al patrimonio y van en contra de la ciudadanía.

\section{DISCUSIÓN Y CONCLUSIONES}

Ante los criterios para ubicar y construir una ciudad la realidad americana impuso nuevos modelos de ciudad colonial repetidos durante varios siglos. Las ciudades de América Latina fundadas a partir de una voluntad ibérica del siglo XVI supieron conservar sus espacios originarios, marcados por las influencias arquitectónicas y urbanísticas europeas, sobre las cuales los elementos específicos de las culturas locales o del mestizaje se ejercieron conjuntamente. De esta manera, la influencia de España respecto al emplazamiento y organización sobre ciertas ciudades y cascos históricos de América Latina, a través de ordenanzas y leyes de Indias lograron con el plano de ajedrez permitió un fácil reparto de solares (Lucena, 2008). El casco urbano colonial es un punto importante en la economía de la ciudad que muestra el violento paso de un capitalismo sin posibilidad de impulsar un crecimiento económico con igualdad. Por esta razón las ciudades objeto de esta investigación se encuentran entre las de mayor interés histórico, La Habana, Quito y Puebla, así como Lima o México que además de surgir durante el siglo XVI, conservan su valor del patrimonio cultural tangible de la época colonial. Sin embargo, hay pocos estudios sobre los cambios en la estructura de los cascos urbanos preindustriales comparables con los cascos antiguos de ciudades europeas. No obstante, puede observarse como en las ciudades de la colonia española y portuguesa, con el proceso de industrialización los estilos arquitectónicos adoptan tendencias estilísticas de Europa y de Norte América. Dentro de las transformaciones funcionales se amplía el distrito central de negocios, más allá de lo límites de la ciudad colonial, debido al carácter económico de la localización.

Podemos observar entonces como a partir del siglo XX la ciudad se expande y con el cambio de uso del suelo hay mayor demanda comercial y de servicios que transforman viviendas y patios interiores. Se produce un proceso de concentración de la administración pública central que perdura en edificios tradicionales representativos en torno a la Plaza mayor (Gormsen, 1993). No obstante, rebasa los límites de la ciudad colonial, respetando las formas de construcción tradicional (Bogotá, Caracas, Lima, México, Puebla y Quito). En Quito declarado patrimonio cultural de la humanidad en 1978 el instrumento de conservación más importante fue el Plan Odriozola que mezcla ideas urbanísticas europeas y norteamericanas encaminadas a la gestión urbana. Es referente de protección de su centro histórico para su protección siendo la primera ordenanza en Latinoamérica (Zambrano, 1991). Otro aspecto relevante surge en 1967 con la promulgación de las Normas de Quito, para la protección del Patrimonio Cultural. Sin embargo, en la actualidad existen varios problemas de degradación de centro histórico ya que los antiguos propietarios se marcharán, y las casonas se rentaron a las clases sociales bajas y nuevos comerciantes cuya desvalorización altero segmentos e inmuebles históricos para construir nuevos edificios (Mertins, 2006).

Por otra parte, la Habana, declarada patrimonio cultural de la humanidad en 1982 es una ciudad con influencias americanas, europeas, africanas y asiáticas. Dos hechos importantes fueron la instauración de un puerto único y la fortificación de la ciudad. Es un referente de conservación del patrimonio desde 1959 a partir del Plan Director de La Habana. Recientemente su centro histórico ha sido declarado "Zona de Alta significación para el turismo". La Oficina del Historiador de la Ciudad de La Habana (OHCH), con la restauración de La Habana Vieja aumento los avances técnicos en planeación urbana. De esta manera la Habana en la actualidad es un referente de la conservación y divulgación de su diversidad cultural.

Por último, la ciudad de Puebla declarada como Ciudad Patrimonio cultural de la humanidad en 1987, ha ido generando políticas públicas e instrumentos para la conservación del centro histórico y de su patrimonio cultural, que al igual que Quito buscan un equilibrio entre el uso habitacional y de servicios. En los últimos años instrumentos y programas como el programa parcial de desarrollo urbano sustentable del centro histórico del municipio de Puebla y su Plan de Manejo a través de un análisis integral buscan generar soluciones a algunas amenazas que enfrenta el patrimonio cultural. Sin embargo, existen acciones y proyectos turísticos y especulativos tanto en el centro histórico como en sus barrios que afectan al patrimonio y fragmentan a la sociedad beneficiando a ciertos actores, por lo que aún no se ha logrado una visión de sustentabilidad a largo plazo. 
Actualmente, podemos decir que una similitud entre estas ciudades se encuentra en la compleja interacción institucional para la elaboración de políticas públicas y toma de decisiones que realmente protejan su valor histórico y humano. Encontramos que en la mayoría de los casos estas se encuentran encaminadas a proyectos inmobiliarios que impulsan la existencia de hoteles, restaurantes y actividades orientadas al sector turístico y de servicios, aprovechando que el centro de la ciudad sigue constituyendo el destino más importante del tráfico interurbano, no obstante, estas acciones no tienen un impacto real sobre la sociedad residente lo pone en riesgo la preservación del patrimonio cultural inmaterial. De esta manera, esta investigación fortalece la indagación respecto a las políticas de intervención que están siendo aplicadas en ciudades latinoamericanas como Puebla, que, a pesar de contar con nombramiento de Patrimonio Cultural de la Humanidad desde hace 32 años, las estrategias culturales se han dirigido al sector turístico y cambio de uso del suelo de habitacional a comercio y servicios que al igual que en Quito pone en riesgo la habitabilidad de estas ciudades. Además de hacer evidente el riesgo y dificultad de conservar y preservar el patrimonio cultural material e inmaterial que hace de sus centros históricos un referente de simbolismo e identidad a nivel internacional. De esta manera se da paso a nuevas líneas de investigación respecto a la necesidad de una adecuada gestión para la protección y salvaguarda del patrimonio cultural, así como la gestión participativa para el desarrollo local comunitario y recuperación de oficios y tradiciones, donde la Habana es un referente que debemos considerar en temas de economía solidaria que pongan en valor toda la riqueza histórica y cultural de las ciudades novohispanas.

\section{Agradecimientos}

Para el fortalecimiento de las líneas de investigación este proyecto está vinculado a Vicerrectoría de Investigación y Estudios de Posgrado, VIEP- BUAP No. 100443088-VIEP2019 RARN-ING19-G, Haciendo Ciencia, PRODEP 511-6/17-8017. Y proyecto CSO2016-75236-C2-1-R. (AEI/FEDER, UE)

\section{REFERENCIAS}

Achig, L. (1983). El proceso urbano de Quito. 1. Quito: Ediciones Ciudad.

Arjona, M. (1982). Fortificaciones de la Ciudad de La Habana. $1^{\circ}$. La Habana: Ministerio de Cultura.

Armada, J. D. (1798). Nautical Chart and City Map of Havana, Cuba. Recuperado de Geographicus: https://www.geographicus.com/P/AntiqueMap/Havana-delrio-1798

Berriz, A. F. (2017). Cuban Heritage. Recuperado de https://www.cubanheritage.com/la-nueva-habana-el-plan-maestrode-julio-cesar-perez/

Biffis, A. G. (2013). Los centros históricos Latinoamericanos: Estrategias de intervención, renovación y gestión. Periodo 19802010. Recuperado de https://upcommons.upc.edu/bitstream/handle/2099/14475/GONZALEZ_Alejandra.pdf

Blasco, J. A. (2016). La habana colonial: la "Habana Vieja" y la ciudad extramuros antes de 1898. Madrid, España. Recuperado de Urban Networks: http://urban-networks.blogspot.com/2016/02/la-habana-colonial-la-habana-vieja-y-la.html

Cabrera Hanna, S. (2017). El Centro Histórico de Quito en la planificación urbana (1942-1992). Discursos patrimoniales, cambios espaciales y desplazamientos socioculturales. Territorios, (36), 189-215. doi:https://doi.org/10.12804/revistas.urosario.edu.co/territorios/a.5249

Correia, M. (2007). Teoría de la conservación y su aplicación al patrimonio en tierra. Auntes, 20 (2), 202-219.

Cruz de los Ángeles, J. A., Pérez Paredes, A., Torralba Flores, A., \& Bonilla Gasca, B. (2017). Puebla, México “Ciudad Patrimonio de la Humanidad". International Journal of Scientific Management and Tourism, 3 (2), 273-298.

Diaz del Castillo, B. (1998). Historia verdadera de la conquista de la Nueva España. 16,558. Madrid: Historia.

Duviols, J. P. (1999). Percepciones e imágenes del mundo americano a través de los primeros testimonios. Coord. por Frank Moya Pons y Franklin Pease García-Yrigoyen. Historia general de América Latina, Vol. 2. El primer contacto y la formación de las nuevas sociedades (Vol. II). Madrid.

Echeverría, A. (2008). El centro histórico ¿concepto o criterio en desarrollo? Arquitectura y urbanismo, XXIX (2-3), 11,15 y 18. Recuperado de https://www.redalyc.org/pdf/3768/376839855003.pdf 
Fuentes, S. L. (2011). Puebla y su fundación (parte II). Recuperado de Puebla, México: https://www.yosoypuebla. com/2011/07/puebla-y-su-fundacion-parte-ii/

Gavira, C. (1983). Las ciudades en Cuba: fundacion y desarrollo (s. XVI). Les villes à Cuba: Fondation et développement (XVI siècle). Ciudad y Territorio. Revista de Ciencia Urbana (57-58), 101-110.

Glaeser, E. (2011). Cities, productivity, and quality of life. Science, 333(6042), 592-594. doi:10.1126/science.1209264

Gobierno Municipal (2015). Programa Parcial de Desarrollo Urbano Sustentable del Centro Histórico del Municipio de Puebla. Puebla: Puebla, México. Publicado en el periódico oficial del Estado de Puebla el día viernes 23 de octubre de 2015. N 17. Quinta sección.

González, F. (1993). Desarrollo Metropolitano, análisis y perspectivas. Puebla: Benemérita Universidad Autónoma de Puebla.

Gormsen, E. (1993). La rehabilitación de los cascos urbanos en América Latina. Problemas y perspectivas. 71-79. Mainz, Alemania: Instituto de Geografía, Universidad de Mainz.

Hardoy, J. E. y Geisse, G. (1972). Políticas de desarrollo urbano y regional en América Latina. Buenos Aires: Edic. SIAP.

Heineberg, H. (1996). Desarrollo y estructura de antiguas ciudades coloniales españolas en América del Sur según los planos de Lima (1872), Bogotá (1852) y Montevideo (1865). Tras las huellas: dos viajeros alemanes en tierras latinoamericanas. Bogotá: Banco de la República.

Landaeta, P., \& Espinoza, R. (2013). El fin histórico de la ciudad. Acerca del vínculo entre arquitectura y policía. Ideas y Valores, 62 (151), $169-194$.

Lucena, M. (2008). La fundación de América a partir de su historia urbana. Urbanismo y vida urbana en Iberoamérica colonial. Bogotá: Alcaldía Mayor de Bogotá.

Martin L. M. A. y Múscar, B. E. (1992). Proceso de urbanización en América del Sur. Modelo de ocupación del espacio. Madrid: Mapfre.

Mertins, G. (2006). La renovación de los centros históricos en Latinoamérica: Fases, conceptos y estrategias. Colombia: Memorias, Universidad del Norte.

Municipio del distrito metropolitano de Quito. (2017). Recuperado de Secretaria de territorio, archivo histórico: http:// sthv.quito.gob.ec/archivo-historico/

Nicolini, A. (2005). La ciudad hispanoamericana: medieval, renacentista y americana. Atrio. Revista de historia del arte, $10(11), 27-36$.

Oficina del Historiador (2011). La Plaza Vieja de la Habana proceso de recuperación. Junta de Andalucía.

Ramírez Rosete, N. L., Basilio Calderón, C., \& Milián Ávila, M. G. (2017). Gestión participativa en la elaboración de estrategias de revitalización urbana para el barrio histórico de San José, Puebla. Nova scientia, 39. doi:https://doi. org/10.21640/ns.v9i18.680

Rodríguez Aloma, P. (2008). El centro histórico: del concepto a la accion integral. Revista Científica de la Organización Latinoamericana y del Caribe de Centros Históricos (1), 51-64.

Rodríguez Aloma, P. (2016). “Nada urbano me es ajeno” El caso de La Habana Cuba. Patrimonio Mundial, 81, 44-46.

Rocha, X. C. (2011). Posgrado UNAM publicaciones. Recuperado de http://www.posgrado.unam.mx/publicaciones/ant_ omnia/11/02.pdf

Sahady Villanueva, A., \& Gallardo Gastelo, F. (2004). Centros históricos: El auténtico ADN de las ciudades. Revista Invi, 51(9), 9-30. INVI.

Sánchez, L. M., \& Woolfson, O. (2016). Centro histórico de Quito: aportes para reflexionar sobre la preservación de las casas patio desde el estado de concientización usuaria. Contexto. Revista de la Facultad de Arquitectura de la Universidad Autónoma de Nuevo León, 10(12), 29-38.

Sanz, J. L. (2008). Aprendiendo de Puebla: Conservación del Patrimonio urbano para una ciudad habitable. Recuperado de Mapa de Carlos Montero Pantoja, BUAP, Latin American Network Information Center: http://lanic.utexas.edu/project/etext/llilas/vrp/puebla.pdf

Secretaría de Territorio Quito (2017). Distrito Metropolitano de Quito. Recuperado de http://sthv.quito.gob.ec/archivo-historico/

Tojo, J. F. (2000). La protección del patrimonio urbano (Vol. 2). Ediciones Akal.

UNESCO. (2019). Organización de las Naciones Unidas para la Educación, la Ciencia y la Cultura. Recuperado de http:// www.unesco.org/new/es/santiago/culture/cultural-heritage/ 
Val, J. R. (2011). Rehabilitación Urbana en España (1989-2010). Barreras actuales y sugerencias para su eliminación. Informes de la Construcción, 63(Extra), 5-20. doi: https://doi.org/10.3989/ic.11.060

Venegas, C. (1990). La urbanización de las murallas: dependencia y modernidad. $3^{\circ}$. La Habana: Letras cubanas.

Villacres, J. C. (21 de mayo de 2014). Arquitectura ecuatoriana. Recuperado de http://arquitecturaecuatoriana.blogspot. com/2014/05/quito-el-plan-jones-odriozola-1942-1945.html

Zamorano, M. (1991). Quito: tradición hispánica en la geografía de una ciudad andina. Eria (24), 75-82. 